\title{
Atomically Resolved Structural and Chemical Investigation of Single MXene Sheets
}

\author{
Linda Karlsson, Jens Birch, Joseph Halim, Michel W. Barsoum, Pe and Persson
}

\section{Linköping University Post Print}

\section{Tweet}

N.B.: When citing this work, cite the original article.

Original Publication:

Linda Karlsson, Jens Birch, Joseph Halim, Michel W. Barsoum, Pe and Persson, Atomically Resolved Structural and Chemical Investigation of Single MXene Sheets, 2015, Nano letters (Print), (15), 8, 4955-4960.

http://dx.doi.org/10.1021/acs.nanolett.5b00737

Copyright: American Chemical Society

http://pubs.acs.org/

Postprint available at: Linköping University Electronic Press

http://urn.kb.se/resolve?urn=urn:nbn:se:liu:diva-120927 


\title{
Atomically resolved structural and chemical investigation of single $\mathrm{MXene}$ sheets
}

\author{
Linda H. Karlsson, ${ }^{\dagger}$ Jens Birch, ${ }^{\dagger}$ Joseph Halim, ${ }^{\dagger, \ddagger}$ Michel W. Barsoum, ${ }^{\dagger, \ddagger}$ and \\ Per O.Å. Persson ${ }^{*, \dagger}$ \\ Department of Physics, Chemistry and Biology, Linköping University, SE-581 83 \\ Linköping, Sweden, and Department of Materials Science $\mathcal{G}$ Engineering, Drexel \\ University, Philadelphia, Pennsylvania 19104, United States \\ E-mail: perpe@ifm.liu.se
}

\begin{abstract}
The properties of two dimensional (2D) materials depend strongly on the chemical and electrochemical activity of their surfaces. MXene, one of the most recent additions to $2 \mathrm{D}$ materials, shows great promise as an energy storage material. In the present investigation, the chemical and structural properties of individual $\mathrm{Ti}_{3} \mathrm{C}_{2}$ MXene sheets with associated surface groups are investigated at the atomic level by aberration corrected STEM-EELS. The MXene sheets are shown to exhibit a non-uniform coverage of O-based surface groups which locally affect the chemistry. Additionally, native point defects which are proposed to affect the local surface chemistry, such as oxidized titanium adatoms $\left(\mathrm{TiO}_{x}\right)$, are identified and found to be mobile.
\end{abstract}

\footnotetext{
* To whom correspondence should be addressed

$\dagger$ Department of Physics, Chemistry and Biology, Linköping University, SE-581 83 Linköping, Sweden

${ }^{\ddagger}$ Department of Materials Science \& Engineering, Drexel University, Philadelphia, Pennsylvania 19104, United States
} 
Keywords: MXene, $\mathrm{Ti}_{3} \mathrm{C}_{2} \mathrm{~T}_{x}$, Aberration corrected STEM, Surface Chemistry, Surface termination

Since the discovery of graphene, interest in other 2D materials such as boron nitride, ${ }^{1,2}$ transition metal dichalcogenides ${ }^{2,3}$ and, more recently, MXenes has increased significantly. The latter originate from the MAX phases, consisting of a transition metal (M), an Agroup (A) element and $\mathrm{C}$ or $\mathrm{N}(\mathrm{X}){ }^{4}$ The significance of the MAX phases stems from their laminated structure, where $\mathrm{M}_{n+1} \mathrm{X}_{n}$ sheets are interleaved with atomically thin A layers. ${ }^{5,6}$ The M-X bonds consist of a mixture of covalent, metallic, and ionic bonds ${ }^{6}$ making MXene exceptionally strong and hence appealing for new applications. ${ }^{6-8}$

MXenes are synthesized from the MAX phases by removal of A-layers through chemical etching, resulting in stand-alone $2 \mathrm{D}$ sheets. ${ }^{5,6,8,9}$ Upon etching of $\mathrm{Ti}_{3} \mathrm{AlC}_{2}$, the $\mathrm{Ti}$ - $\mathrm{Al}$ bonds are replaced by Ti-O, Ti-OH and/or Ti-F bonds ${ }^{5,6,9,10}$ such that the $\mathrm{O}, \mathrm{OH}$, and $\mathrm{F}$ surface groups terminate the MXene surface. Additionally, etching with $\mathrm{NH}_{4} \mathrm{HF}_{2}$ results in $\mathrm{NH}_{3}$ or $\mathrm{NH}_{4}^{+}$molecules intercalated between the sheets. ${ }^{9}$ The resulting sheets are designated $\mathrm{M}_{n+1} \mathrm{X}_{n} \mathrm{~T}_{x}$-IC, where $\mathrm{T}_{x}$ correspond to the surface groups and IC to the intercalated compounds. ${ }^{9}$ To date, a number of MXenes have been fabricated, ${ }^{5,11-14}$ where the most investigated one, $\mathrm{Ti}_{3} \mathrm{C}_{2}$, is further investigated herein. The $\mathrm{Ti}_{3} \mathrm{C}_{2}$ MXene unit cell consists of $3 \mathrm{Ti}$ and $2 \mathrm{C}$ atoms organized in a close-packed structure ${ }^{6,10}$ (see Figure 1). Every third position in the [0001] projection consists of a single Ti-atom, while a $\mathrm{C}$ atom is positioned either above or below the remaining two. Surface groups of low mass elements such as those mentioned above have been proposed to attach to the sheet in either config. A or B. ${ }^{6,10,15 ?}$ Further low symmetry positions include the less stable atop and bridge. Recently, it was shown that the plasmon frequencies of multiple MXene sheets are a weak function of the number of sheets. ${ }^{16}$ However, MXene properties can in principle be tuned by surface groups $^{6,7,17-19}$ and by native defects. ${ }^{10}$

While there have been a number of theoretical investigations on MXenes and their properties, e.g., ${ }^{7,15}$ there have been few, if any, direct observations at atomic resolution which 

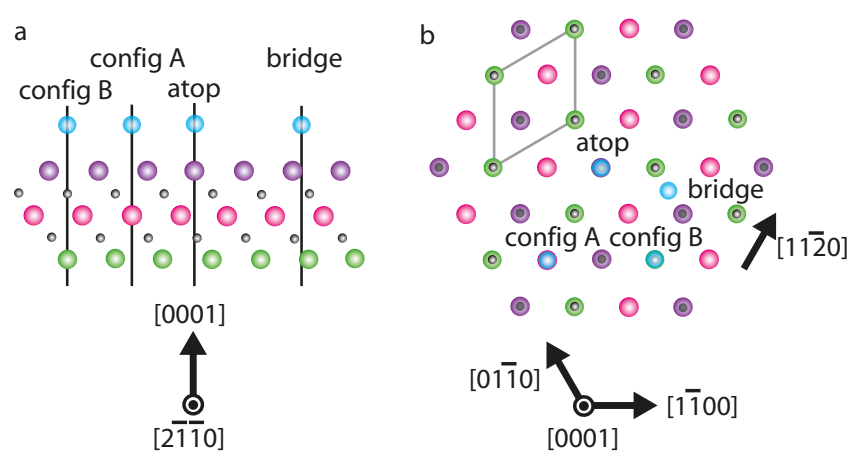

Figure 1. Schematic view of a single $\mathrm{Ti}_{3} \mathrm{C}_{2} \mathrm{~T}_{x}$ sheet. (a) Side view showing three Ti-layers (green, pink, lilac) and two intermediate $\mathrm{C}$ layers (black) as well as $\mathrm{T}_{x}$ positions (blue) along

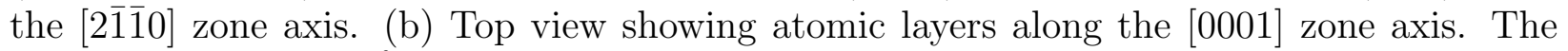
unit cell (with $a \sim 3 \AA^{10}$ ) is outlined with solid lines. In both a and b, the various adatom locations - config. A, config. B, atop and bridge - used herein are defined.

is crucial to advance the understanding of MXenes. Here, we investigate the structural properties of single, double and multiple sheets of $\mathrm{Ti}_{3} \mathrm{C}_{2} \mathrm{~T}_{x}$ with attached surface groups by atomic-resolution scanning transmission electron microscopy (STEM). The elemental and chemical properties were further investigated by electron energy loss spectroscopy spectrum imaging (EELS SI). Through these methods we identify the atomic structure of the MXene sheets as well as intrinsic defects, surface and edge terminations by the partial coverage of surface groups. We also report on the mobility and migration of intrinsic defects and surface groups.

$\mathrm{Ti}_{3} \mathrm{C}_{2} \mathrm{~T}_{x}$ powder was produced from $\mathrm{Ti}_{3} \mathrm{AlC}_{2}$ which was prepared by ball-milling $\mathrm{Ti}_{2} \mathrm{AlC}$ (> 92 wt\%, 3-ONE-2, Voorhees, NJ) and TiC (99\%, Johnson Matthey Electronic, NY) powders in a 1:1 molar ratio for $24 \mathrm{~h}$ using zirconia balls. The mixture was annealed at 1350 ${ }^{\circ} \mathrm{C}$ for $2 \mathrm{~h}$ in argon. The sintered compact was converted to a powder by milling. $\mathrm{Ti}_{3} \mathrm{C}_{2}$ MXene powder was prepared by immersing $2.5 \mathrm{~g}$ of $<400$ mesh $\mathrm{Ti}_{3} \mathrm{AlC}_{2}$ powder in $1 \mathrm{M}$ of $\mathrm{NH}_{4} \mathrm{HF}_{2}$ (Sigma Aldrich, USA) solution for 5 days. After treatment the suspension was washed several times using deionized water and centrifuged to separate the settled powder from the supernatant. The settled powders were removed from vials using ethanol and dried at room temperature. TEM samples were prepared by crushing the powder in a mortar and 
dispersing the powder on a holey carbon $\mathrm{Cu}$ TEM-grid, followed by immediately insertion into the TEM.

Characterization was performed using the Linköping double corrected FEI Titan ${ }^{3}$ 60300, equipped with a high brightness gun (XFEG), monochromator and Quantum ERS-GIF. Thickness determination of MXene sheets was performed by intensity variations in STEM HAADF images. Compositional analysis was performed by electron energy loss spectroscopy spectrum imaging (EELS-SI) using dual-EELS. All analysis was performed at $60 \mathrm{kV}$ to minimize beam damage and SI was performed using $0.1 \mathrm{nA}$ beam current. EELS intensities were normalized with respect to the Ti peak. The composition was determined by averaging over spectra in the area of interest and using the built-in functions in Gatan Digital Micrograph with uncertainty in the stoichiometry calculated by the variance formula using the ratio of $\mathrm{C}$ and Ti. Atomic resolution STEM HAADF image was filtered using FFT filtering and Gaussian blur.

The sheets investigated here are part of a macroscopic flake consisting of multiple sheets which was suspended in vacuum by the holey carbon support (Figure 2a). The investigated area (white square in Figure 2a) was located at the edge of the flake and is magnified to atomic resolution in Figure $2 \mathrm{~b}$ (areas of interest indicated in Figure 2c). Contrast variations between the sheets relative to the vacuum level identify thicknesses corresponding to a single and double sheet (see Supporting Information Figure 1), which both exhibit the expected close-packed appearance. STEM image contrast exhibit a $\sim Z^{2}$ dependence on the atomic mass, hence, among the present MXene and potential etchant elements, it then follows that the apparent structure corresponds to Ti-sites. Despite the fact that the A-layers have been removed from the parent MAX structure, the atomic positions of the two sheets remain laterally aligned, which is apparent from the discrete representation of the double sheet (see Figure $2 \mathrm{~b}$ ) and is consistent with previous reports. ${ }^{5}$

A variation in the lattice appereance across the single MXene sheet is observed (Figure $2 \mathrm{~b}$ ). Although inherent bending is observed in other $2 \mathrm{D}$ materials such as graphene, ${ }^{20}$ here 


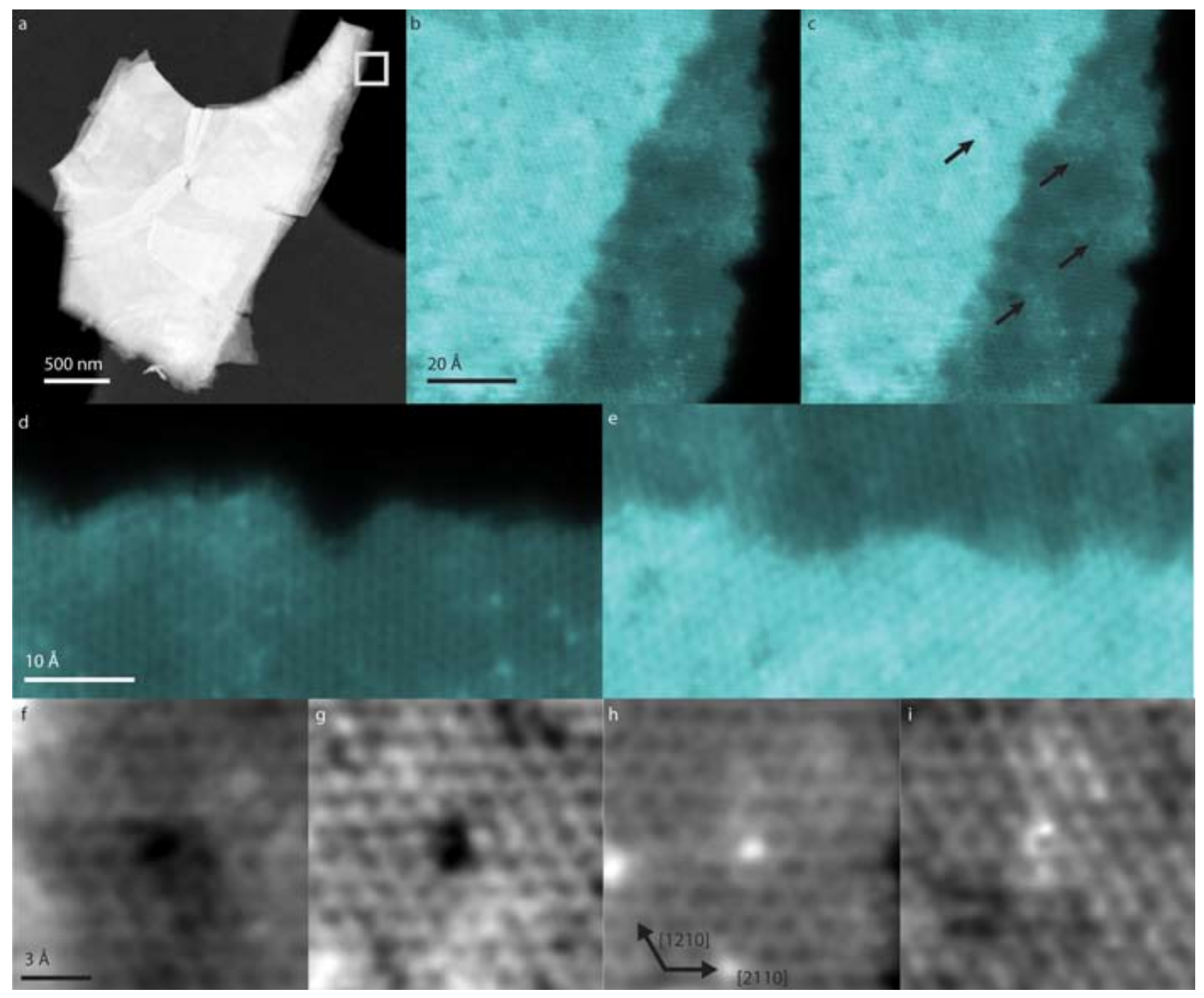

Figure 2. HAADF STEM images of $\mathrm{Ti}_{3} \mathrm{C}_{2} \mathrm{~T}_{x}$ sheets. (a) A STEM HAADF image of a typical MXene particle in the [0001] projection (scale bar $=500 \mathrm{~nm}$ ). (b) Atomic resolution image of inlaid square in (b). (c) Positions of surface groups. (d) Edge of a single sheet. (e) Double sheet termination, where a sheet terminates on top of another sheet. (f) Ti vacancy in a single MXene sheet. (g) Single vacancy in the double sheet. (h) Ti adatom on a single MXene sheet. (i) Ti adatom on double sheet. 
the variation is attributed to irregularities and strain caused by surface groups (described below) on the top and bottom surfaces as well as intrinsic defects. In contrast, the double sheet appears more uniform, displaying a well-defined lattice (Figure 2b).

Structural variations are also observed along the edges of both sheets indicating local order (sharp edges) and disorder (diffuse edges) on the atomic level (see Figure 2d, e). At the ordered edges, the sheets are terminated by $\{11 \overline{2} 0\}$ facets (compare Figure $1 \mathrm{~b}$ ). The sharp contrast of the atoms at the ordered edges indicates termination by Ti atoms, while diffuse contrast indicates termination by lower mass atoms. Note that the single sheet edge is terminated in a more ordered fashion than the double sheet edge. In analogy to the half unit cell surface steps observed in the parent MAX phases, ${ }^{21}$ it is suggested that surface bound material is more easily attracted by step edges between sheets, than at edges of sheets which are terminating in vacuum.

Intrinsic defects are observed, such as vacancies (Figure 2f, g) and adatoms (Figure 2h, i), which correspond to $\mathrm{Ti}$ vacancies and adatoms as identified by the strong contrast variations (see Supporting Information Figure 1). The lattice appears to relax around vacancies, and Ti adatoms are observed to be positioned above Ti atoms in the MXene lattice (corresponding to config. A, config. B and atop in Figure 1). The diffuse contrast attracted to the Ti adatoms (see Supporting Information Figure 1) is inferred to correspond to $\mathrm{O}$ as a consequence of the formation of $\mathrm{TiO}_{x}$ groups due to the high reactivity between $\mathrm{Ti}$ and $\mathrm{O} .{ }^{22}$

The MXene sheets also exhibit extended areas with diffuse image contrast (indicated by arrows in Figure 2c). These areas are interpreted as surface groups of low mass elements terminating the MXene surfaces. Remaining lower contrast areas are suggested to exhibit none or partial (fraction of top or bottom surfaces) terminations by surface groups, i.e., the surfaces are unterminated.

According to the EELS measurements, the average composition, neglecting edge effects across a single MXene sheet, is 47, 33, 20, and 3 at.\% for Ti, C, O, and $\mathrm{N}$ respectively. For the double sheet, the corresponding composition was 46, 29, 24, and 2 at.\%, with 1 
at.\% of F, while for multiple sheets 40,24, 31, 2, and 3 at.\% respectively (see Figure 3 and Supporting Information Figure 2 and Table 1). The composition was corroborated by XPS, see Supporting Information Figure 3 and Supporting information Table 2, 3.
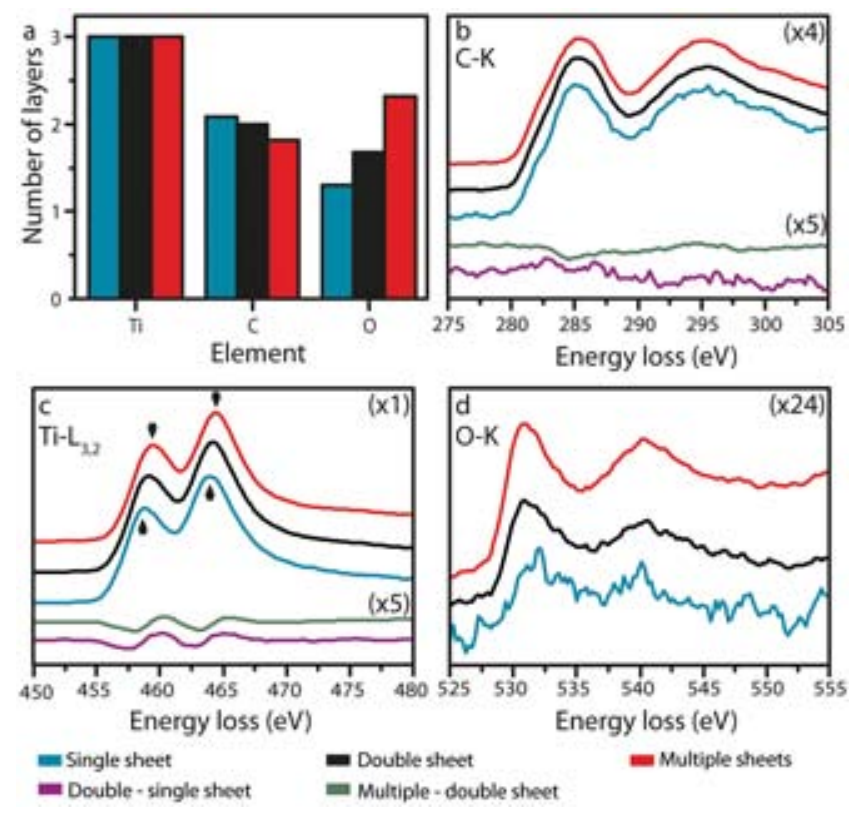

Figure 3. EELS averaging over $\mathrm{Ti}_{3} \mathrm{C}_{2} \mathrm{~T}_{x}$ sheets. (a) Histogram of EELS averaging of a single sheet, double sheet and multiple sheets display the stoichiometry of Ti, C and O. (b) EELS spectra of the C-K-edge with a differential spectra. (c) EELS spectra of the Ti- $\mathrm{L}_{3,2}$-edge, where the arrows indicate a shift of the peaks, and with differential spectra.

The STEM image (Figure 2b) indicates a nearly perfect Ti occupancy in the MXene sheets, thus the MXene can be described as $\mathrm{T}_{3} \mathrm{C}_{x} \mathrm{~T}_{y}$, where $x$ and $y$ are variables. Normalizing to three Ti layers per sheet, the compositions for the different thicknesses (averaged to layers per sheet) are shown in the histogram of Figure 3a, which indicate a decrease in $\mathrm{C}$ and a strong increase in $\mathrm{O}$ with increasing MXene thickness. The average $\mathrm{C}$ composition of the single sheet gives $x=2.08 \pm 0.09$, which is slightly higher than the ideal stoichiometry of $\mathrm{Ti}_{3} \mathrm{C}_{2} \mathrm{~T}_{y}$, and the reported stoichiometry of $\mathrm{Ti}_{3} \mathrm{AlC}_{1.8}$ for the parent MAX phase. ${ }^{23}$ This indicates a small presence of $\mathrm{C}$ on the surface which may originate from the etching process. Interestingly, the composition is different at the edge of the single sheet where $x=1.84 \pm 0.07$ (see Supporting Information Table 1 and Supporting Information Figure 2). The composition measured on the double sheet gives $x=2.00 \pm 0.09$. On multiple sheets, 
where the contribution from the MXene-vacuum interface is reduced, the composition gives $x=1.82 \pm 0.08$, which correspond to the parent MAX phase stoichiometry. When averaging over areas exhibiting pronounced contrast from surface groups, C is slightly reduced (to $x=2.02 \pm 0.09$ for single sheet and $x=2.00 \pm 0.09$ for double), while increasing in areas without surface groups, $(x=2.11 \pm 0.09$ for single and $x=2.11 \pm 0.09$ for double $)$. Thus, excess C appears to be separated from surface groups.

The $\mathrm{O}$ averaged across the single sheet corresponds to $y=1.30 \pm 0.04$, or an approximate coverage of $2 / 3$ on both top and bottom surfaces. On the double sheet the average composition increases, $y=1.68 \pm 0.07$, which indicate a saturation of O between the sheets and a higher coverage on the MXene-vacuum surfaces compared to the single sheet. Close inspection of the EELS spectrum images reveals that the $\mathrm{O}$ concentration varies locally (see Supporting Information Table 1 and Supporting Information Figure 2), such that areas on the single sheet, which are covered by surface groups (indicated in Figure 2c), show a local increased $\mathrm{O}$ content corresponding to $y=1.97 \pm 0.08$. This corresponds to saturation on both top and bottom surfaces and identifies the surface groups as O-based. The single sheet edge exhibit $y=1.00 \pm 0.03$, indicating that surface groups refrain from the edge. In contrast, the double sheet edge exhibit $y=1.88 \pm 0.08$ which suggest that the diffuse contrast observed at the step-edge corresponds to $\mathrm{O}$ and that the step-edge acts as a getter for these. The origin of the local variation of $\mathrm{O}$ coverage is proposed to occur through surface reconstruction. Upon exposure to vacuum and a reduced $\mathrm{H}_{2} \mathrm{O}$ vapour pressure, the Ti-bound $\mathrm{OH}$ on the MXene surface decomposes to $\mathrm{H}_{2} \mathrm{O}$ and $\mathrm{O}$ through the equilibrium driven reaction $\mathrm{OH}+\mathrm{OH} \rightarrow \mathrm{H}_{2} \mathrm{O}+\mathrm{O} .{ }^{24}$ The water molecule desorb and the remaining $\mathrm{O}$ atom is suggested to be bound to $\mathrm{Ti}$ atoms in a fcc position. ${ }^{15}$

EELS further reveal the presence of $\mathrm{N}$ and F, see Supporting Information Figure 4. XPS identifies the presence of $\mathrm{Ti}$ bound $\mathrm{O}_{x},(\mathrm{OH})_{x}$ and of absorbed $\mathrm{H}_{2} \mathrm{O}$ as well as a small fraction of $\mathrm{TiO}_{2}$. While EELS can identify $\mathrm{O}$ as an element, and spatially connect $\mathrm{O}$ to the surface groups, it is not able to distinguish between molecules. In contrast, XPS is unable 
to distinguish between number of sheets which is reflected in the average composition which is similar to the EELS measurement on multiple sheets, see Supporting Information Figure 3 and Table $2,3$.

In addition to identifying the elemental composition and distribution, EELS reveal a chemical shift of the Ti- $\mathrm{L}_{3,2}$ and $\mathrm{C}-\mathrm{K}$ edges with increasing number of MXene sheets. This is exemplified in Figure 3 where averaged and differential spectra are shown. On average, the $\mathrm{L}_{3}$ peak shifts $0.28 \mathrm{eV}$ between single and double sheets and $0.38 \mathrm{eV}$ between the double and multiple sheets. A similar shift is also observed on the single sheet when comparing areas of high and low $\mathrm{O}$ saturation, indicating a direct relationship. When attached to the MXene surface, $\mathrm{O}$ draws valence charge from $\mathrm{Ti}^{15,25}$ and consequently shifts the $\mathrm{Ti}-\mathrm{L}_{3,2}$ edges to higher energy through Coloumb interactions between core and valence states. ${ }^{26}$ The shape of the $\mathrm{C}$ K-edge is seemingly identical to previously investigated edges for $\mathrm{Ti}_{3} \mathrm{AlC}_{2}{ }^{27}$ and $\mathrm{Ti}_{2} \mathrm{AlC},{ }^{23}$ indicating that $\mathrm{C}$ is bound in a MAX phase-like structure. The $\pi$ and $\sigma$ peaks exhibit minor but apparent shifts between sheets which indicate a small amount of charge transfer also from $\mathrm{C}$ to $\mathrm{O}$ through $\mathrm{Ti}$.

The images shown in Figure 4 are recorded $60 \mathrm{~s}$ after the initial (Figure 2b), both surface groups and intrinsic defects have moved and are apparently mobile. Microscopy was performed at ambient temperature, hence the kinetic energy which is applied to initiate the migration is proposed to originate from momentum transfer from the electron beam. ${ }^{28}$ Between these images the surface groups have ripened into larger islands and migrated towards the edges of the sheets, as well as to the middle of the single sheet (Figure 4c and f). Adatoms on the single sheet have clustered into a triangular-shaped island and coalescence of vacancies is also observed (Figure 4b). Additionally, the edge lengths changes such that it increases on the double sheet and decreases on the single (compare Figure 4c and f).

The observation of migration and ripening of surface groups on the MXene surface is expected as migration may occur even though $\mathrm{O}$ is strongly bound to $\mathrm{Ti}^{15}$ Additionally, $\mathrm{TiO}_{x}$ adatom complexes are also expected to be mobile on the surface as predicted for other 

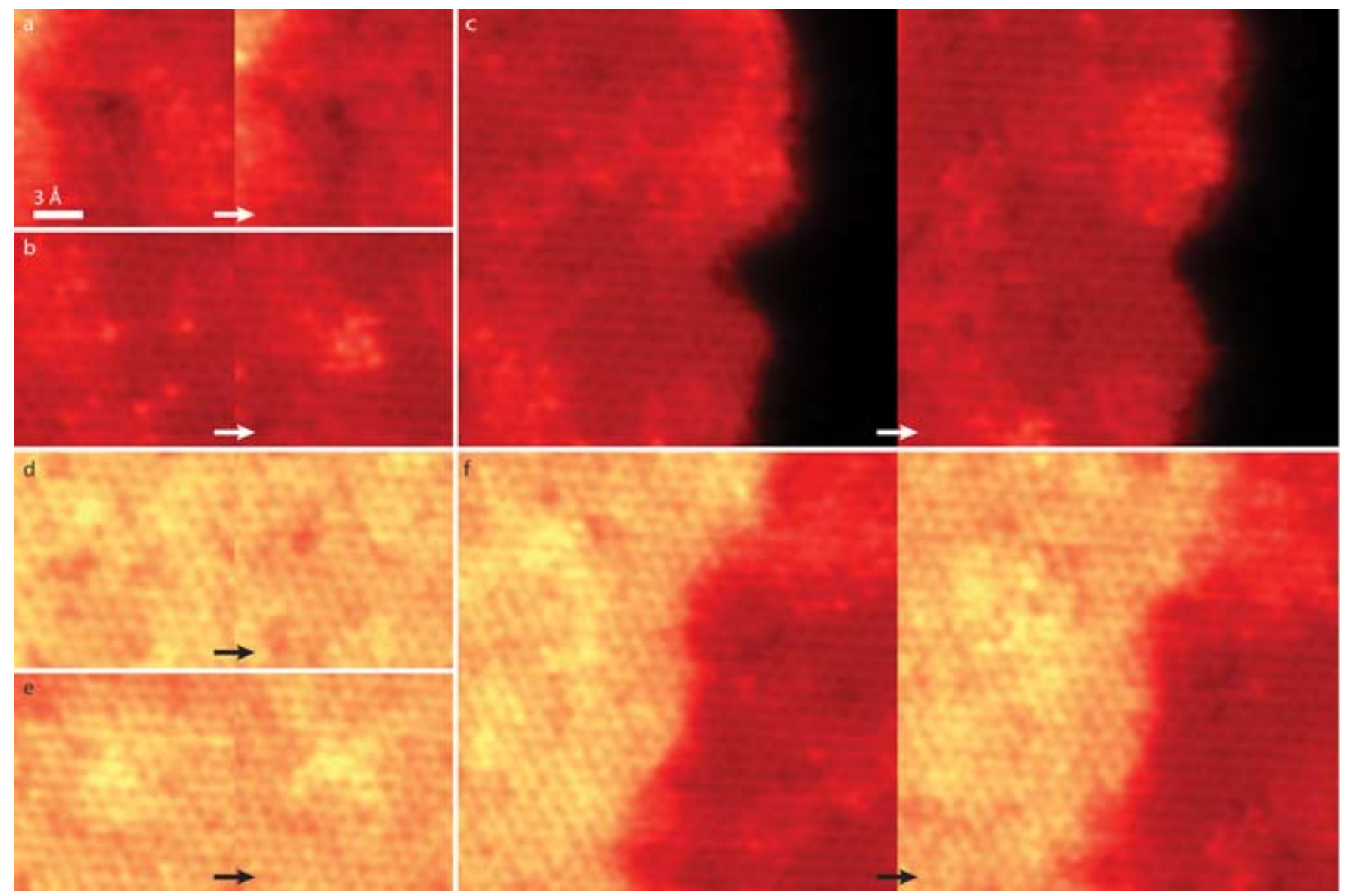

Figure 4. Kinetics on a single and double sheets of $\mathrm{Ti}_{3} \mathrm{C}_{2} \mathrm{~T}_{x}$. (a) A vacancy in single sheet with 60 seconds between acquisitions. (b) Adatom in the single sheet with one minute between acquisitions. (c) The edge of the single sheet with one minute between acquisitions. (d) A vacancy in single sheet with one minute between acquisitions. (e) Adatom in single sheet with one minute between acquisitions. (f) The edge of the double sheet with one minute between acquisitions. 
systems. ${ }^{29}$ The reduction in edge length of the single sheet is in agreement with minimization of edge energy. In contrast, the increase in edge length of the second sheet presumably occurs to accommodate more $\mathrm{O}$ atoms due to the presence of O-based surface groups on the single sheet. In contrast to the edge of the second sheet, surface groups appear to be bound at the edge of the single sheet to a lesser degree. Supposedly, the kinetic energies of the surface groups and adatoms were not high enough to overcome the edge barrier completely and migrate over the edge.

MXenes are a new family of 2D materials with new technological applications. The present investigation reveals insights into the microstructure, surface termination, composition, chemistry and surface kinetics of the most studied MXene to date, $\mathrm{Ti}_{3} \mathrm{C}_{2} \mathrm{~T}_{x}$. For the first time, a single and a double sheet of MXene were observed at atomic resolution, revealing intrinsic defects and sheet coverage of both surface groups and $\mathrm{TiO}_{x}$ adatom complexes. The surface groups have been identified as O-based and are found to draw valence charge from the MXene. The coverage of surface groups is not uniform at MXene-vacuum interfaces, but with full coverage of $\mathrm{O}$ between the sheets. It is also found that the sheets are aligned laterally, as inherited from the parent MAX phase. It is finally observed that atoms and groups at the surfaces of the sheets are mobile, resulting in migration and ripening of surface groups and $\mathrm{TiO}_{x}$ adatom complexes at ambient temperature is observed.

\section{Acknowledgement}

The authors acknowledges The Swedish Research Council for funding and the Knut and Alice Wallenbergs Foundation for support of the electron microscopy laboratory in Linköping. Additionally, the authors thank Joe Greene and Ivan Petrov for fruitful discussions.

\section{Supporting Information Available}

Additional information on characterization by STEM HAADF and XPS. This material is available free of charge via the Internet at http://pubs.acs.org/. 


\section{References}

(1) Fiori, G.; Bonaccorso, F.; Iannaccone, G.; Palacios, T.; Neumaier, D.; Seabaugh, A.; Banerjee, S. K.; Colombo, L. Nature Nanotech. 2014, 9, 768-779.

(2) Novoselov, K. S.; Jiang, D.; Schedin, F.; Booth, T. J.; Khotkevich, V. V.; Morozov, S. V.; Geim, A. K. Proc. Natl. Acad. Sci. U.S.A. 2005, 102, 10451-10453.

(3) Coleman, J. N.; Lotya, M.; O’Neill, A.; Bergin, S. D.; King, P. J.; Khan, U.; Young, K.; Gaucher, A.; De, S.; Smith, R. J.; Shvets, I. V.; Arora, S. K.; Stanton, G.; Kim, H.-Y.; Lee, K.; Kim, G. T.; Duesberg, G. S.; Hallam, T.; Boland, J. J.; Wang, J. J.; Donegan, J. F.; Grunlan, J. C.; Moriarty, G.; Shmeliov, A.; Nicholls, R. J.; Perkins, J. M.; Grieveson, E. M.; Theuwissen, K.; McComb, D. W.; Nellist, P. D.; Nicolosi, V. Science 2011, 331, 568-571.

(4) Eklund, P.; Beckers, M.; Jansson, U.; Högberg, H.; Hultman, L. Thin Solid Films 2010, $518,1851-1878$.

(5) Naguib, M.; Kurtoglu, M.; Presser, V.; Lu, J.; Niu, J.; Heon, M.; Hultman, L.; Gogotsi, Y.; Barsoum, M. W. Adv. Mater. 2011, 23, 4207-4207.

(6) Naguib, M.; Mochalin, V. N.; Barsoum, M. W.; Gogotsi, Y. Adv. Mater. 2014, 26, 992-1005.

(7) Tang, Q.; Zhou, Z.; Shen, P. J. Am. Chem. Soc. 2012, 134, 16909-16916.

(8) Ghidiu, M.; Lukatskaya, M. R.; Zhao, M.-Q.; Gogotsi, Y.; Barsoum, M. W. Nature $2014,516,78-81$.

(9) Halim, J.; Lukatskaya, M. R.; Cook, K. M.; Lu, J.; Smith, C. R.; Näslund, L.; May, S. J.; Hultman, L.; Gogotsi, Y.; Eklund, P.; Barsoum, M. W. Chem. Mater. 2014, 26, 23742381. 
(10) Shi, C.; Beidaghi, M.; Naguib, M.; Mashtalir, O.; Gogotsi, Y.; Billinge, S. J. L. Phys. Rev. Lett. 2014, 112, 125501.

(11) Naguib, M.; Mashtalir, O.; Carle, J.; Presser, V.; Lu, J.; Hultman, L.; Gogotsi, Y.; Barsoum, M. W. ACS Nano 2012, 6, 1322-1331.

(12) Ghidiu, M.; Naguib, M.; Shi, C.; Mashtalir, O.; Pan, L. M.; Zhang, B.; Yang, J.; Gogotsi, Y.; Billinge, S. J. L.; Barsoum, M. W. Chem. Commun. 2014, 50, 9517-9520.

(13) Naguib, M.; Halim, J.; Lu, J.; Cook, K. M.; Hultman, L.; Gogotsi, Y.; Barsoum, M. W. J. Am. Chem. Soc. 2013, 135, 15966-15969.

(14) Mashtalir, O.; Naguib, M.; Mochalin, V. N.; Dall'Agnese, Y.; Heon, M.; Barsoum, M. W.; Gogotsi, Y. Nat Commun. 2013, 4, 1716.

(15) Gan, L. Y.; Huang, D.; Schwingenschlögl, U. J. Mater. Chem. A 2013, 1, 13672-13678.

(16) Mauchamp, V.; Bugnet, M.; Bellido, E. P.; Botton, G. A.; Moreau, P.; Magne, D.; Naguib, M.; Cabioc'H, T.; Barsoum, M. W. Phys. Rev. B 2014, 89, 235428.

(17) Khazaei, M.; Arai, M.; Sasaki, T.; Chung, C.-Y.; Venkataramanan, N. S.; Estili, M.; Sakka, Y.; Kawazoe, Y. Adv. Funct. Mater. 2013, 23, 2185-2192.

(18) Xie, Y.; Kent, P. R. C. Phys. Rev. B 2013, 87, 235441.

(19) Er, D.; Li, J.; Naguib, M.; Gogotsi, Y.; Shenoy, V. B. ACS appl. mater. inter. 2014, $6,11173-11179$.

(20) Meyer, J. C.; Geim, A. K.; Katsnelson, M. I.; Novoselov, K. S.; Booth, T. J.; Roth, S. Nature 2007, 446, 60-63.

(21) Emmerlich, J.; Högberg, H.; Sasvári, S.; Persson, P. O. A.; Hultman, L.; Palmquist, J.P.; Jansson, U.; Molina-Aldareguia, J. M.; Czigány, Z. J. Appl. Phys. 2004, 96, 48174826. 
(22) Vaquila, I.; Vergara, L. I.; Jr., M. C. G. P.; Vidal, R. A.; Ferrón, J. Surf. Coat. Technol. 1999, 122, 67-71.

(23) Hug, G.; Jaouen, M.; Barsoum, M. W. Phys. Rev. B 2005, 71, 024105.

(24) Yamamoto, S.; Bluhm, H.; Andersson, K.; Ketteler, G.; Ogasawara, H.; M Salmeron and, A. J. Phys.: Condens. Matter 2008, 20, 184025.

(25) Carley, A. F.; Chalker, P. R.; Riviere, J. C.; Roberts, M. W. J. Chem. Soc., Faraday Trans. 1987, 83, 351-370.

(26) Terada, S.; Asayama, K.; Tsujimoto, M.; Kurata, H.; Isoda, S. Microsc. Microanal. 2009, 15, 106-113.

(27) Bugnet, M.; Mauchamp, V.; Eklund, P.; Jaouen, M.; Cabioc'H, T. Acta Mater. 2013, $61,7348-7363$.

(28) Egerton, R. F. Microsc. Microanal. 2013, 19, 479-486.

(29) Sangiovanni, D. G.; Edström, D.; Hultman, L.; Chirita, V.; Petrov, I.; Greene, J. E. Phys. Rev. B 2012, 86, 155443. 
Graphical TOC Entry

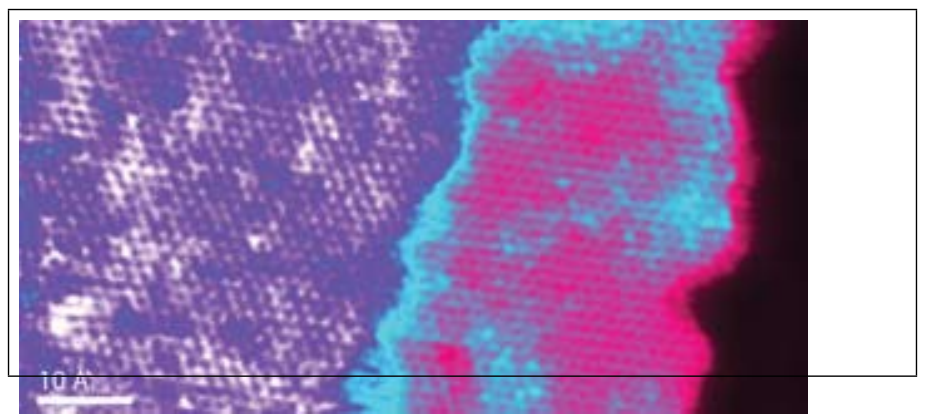




\title{
Atomically resolved structural and chemical investigation of single $\mathrm{MXene}$ sheets
}

\author{
Linda H. Karlsson, ${ }^{\dagger}$ Jens Birch, ${ }^{\dagger}$ Joseph Halim, ${ }^{\dagger, \ddagger}$ Michel W. Barsoum, ${ }^{\dagger, \ddagger}$ and \\ Per O.Å. Persson ${ }^{*} \dagger$ \\ Department of Physics, Chemistry and Biology, Linköping University, SE-581 83 \\ Linköping, Sweden, and Department of Materials Science $\mathcal{G}$ Engineering, Drexel \\ University, Philadelphia, Pennsylvania 19104, United States \\ E-mail: perpe@ifm.liu.se
}

\section{Thickness measurement}

The thickness of the sheets were concluded by intensity profiling. To deduce the intensity over a single sheet and double sheets of MXene, a line profile was drawn over an area in each sheet, see Fig. S1a. The noise present in the line scan is mostly due to the non-uniform coverage of surface groups. The intensity of the double sheet is slightly more than two times the intensity of the single sheet due to the higher coverage of surface groups in-between the sheets. Identification of intrinsic defects was performed by measuring the increase or decrease of intensity over the defects, see Fig. S1b, c.

\footnotetext{
*To whom correspondence should be addressed

${ }^{\dagger}$ Department of Physics, Chemistry and Biology, Linköping University, SE-581 83 Linköping, Sweden

${ }^{\ddagger}$ Department of Materials Science \& Engineering, Drexel University, Philadelphia, Pennsylvania 19104, United States
} 

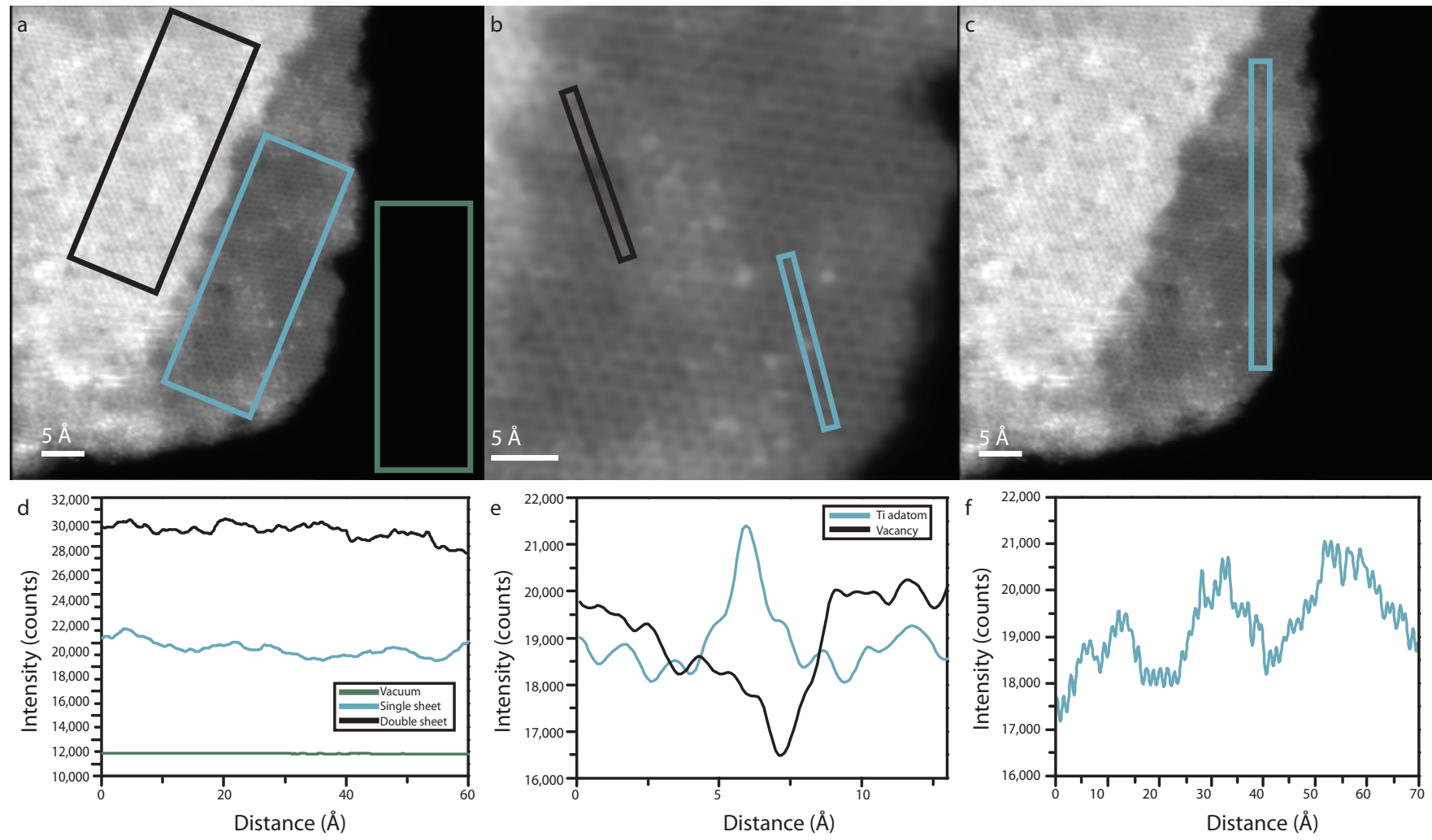

Figure S1. Line profiles across $\mathrm{Ti}_{3} \mathrm{C}_{2} \mathrm{~T}_{x}$. (a) Areas over the sheets where the line profiles for the various sheets. (b) Areas where the line profiles for the adatoms and vacancies. (c) Area where the line profile for the surface groups. (d), Line profile for lines drawn in (a). (e) Line profile for lines drawn in (b). (f) Line profile for lines drawn in (c). 


\section{Composition analysis of multiple sheets}

The composition of various positions of the sheets are shown in Table S1 and the positions are indicated in Fig. S2. Only the single and double sheet were clearly visible as at thicker areas the sheets were stacked on top of each other, see Fig. S2, where the white area indicate more than eight sheets.

Table S1: Elemental composition of MXene sheets. Summary of the elemental distribution for various thicknesses of the MXene sheets.

\begin{tabular}{lllllll}
\hline \multicolumn{7}{c}{ Relative composition (at. \%) } \\
\hline Nr sheets & Area & $\mathrm{C}$ & $\mathrm{N}$ & $\mathrm{Ti}$ & $\mathrm{O}$ & $\mathrm{F}$ \\
\hline 1 & whole sheet & $31 \pm 4$ & $2.6 \pm 0.3$ & $49 \pm 6$ & $20 \pm 2$ & $0.0 \pm 0.3$ \\
2 & whole sheet & $30 \pm 3$ & $2.0 \pm 0.2$ & $46 \pm 5$ & $22 \pm 3$ & $0.4 \pm 0.1$ \\
Multiple & whole sheet & $24 \pm 3$ & $2.2 \pm 0.3$ & $40 \pm 5$ & $31 \pm 4$ & $2.6 \pm 0.3$ \\
1 & surface & $33 \pm 4$ & $3.2 \pm 0.4$ & $47 \pm 6$ & $20 \pm 2$ & $0.0 \pm 0.4$ \\
2 & surface & $29 \pm 3$ & $2.0 \pm 0.2$ & $44 \pm 5$ & $24 \pm 3$ & $0.8 \pm 0.1$ \\
1 & edge & $31 \pm 4$ & $2.9 \pm 0.4$ & $51 \pm 6$ & $17 \pm 2$ & $0.0 \pm 0.3$ \\
2 & edge & $29 \pm 3$ & $1.6 \pm 0.2$ & $43 \pm 5$ & $27 \pm 3$ & $0.0 \pm 0.1$ \\
1 & high contrast & $29 \pm 3$ & $1.3 \pm 0.2$ & $43 \pm 5$ & $28 \pm 3$ & $0.0 \pm 0.3$ \\
2 & high contrast & $28 \pm 3$ & $1.6 \pm 0.2$ & $43 \pm 5$ & $26 \pm 3$ & $1.5 \pm 0.2$ \\
1 & low contrast & $33 \pm 4$ & $3.2 \pm 0.4$ & $47 \pm 6$ & $21 \pm 3$ & $0.0 \pm 0.5$ \\
2 & low contrast & $31 \pm 4$ & $2.0 \pm 0.2$ & $43 \pm 5$ & $23 \pm 3$ & $0.6 \pm 0.1$ \\
\hline
\end{tabular}

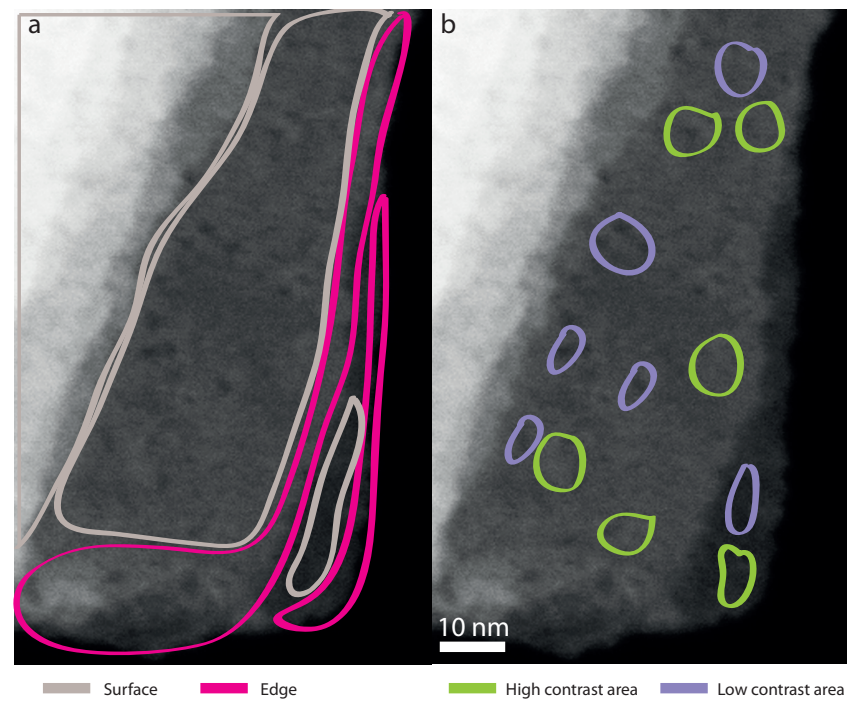

Figure S2. EELS SI of MXene showing areas indicated in Table S1. (a) indication of surface (beige) and edge (magenta) of sheets. (b) indication of high contrast areas (green) and low contrast areas (lilac). 


\section{XPS of $\mathrm{Ti}_{3} \mathrm{C}_{2} \mathbf{T}_{x}$ etched by $\mathrm{NH}_{4} \mathrm{HF}_{2}$}

\section{Experimental details}

X-ray photoelectron spectroscopy (XPS) was used to determine the terminations in $\mathrm{Ti}_{3} \mathrm{C}_{2} \mathrm{~T}_{x}$ etched by $\mathrm{NH}_{4} \mathrm{HF}_{2}$ in the form of cold pressed disk. A Physical Electronics VersaProbe 5000 instrument was used employing a $100 \mu \mathrm{m}$ monochromatic Al-K $\alpha$ to irradiate the sample surface. Photoelectrons were collected by a $180^{\circ}$ hemispherical electron energy analyzer. Samples were analyzed at a $75^{\circ}$ angle between the sample surface and the path to the analyzer. Survey spectra were taken at a pass energy of $117.5 \mathrm{eV}$, with a step size of $0.1 \mathrm{eV}$, which was used to obtain the elemental analysis of the powders. High-resolution spectra of Ti 2p, C 1s, O1s, and F 1s regions were taken at a pass energy of $23.5 \mathrm{eV}$, with a step size of $0.05 \mathrm{eV}$. The spectra were taken after the sample was sputtered with an Ar beam operating at $4.0 \mathrm{kV}$ and $150 \mu \mathrm{A}$ for 40 minutes. All binding energies were referenced to that of the Fermi level $\left(\mathrm{E}_{f}=0 \mathrm{eV}\right)$.

Peak fitting for the high-resolution spectra was performed using CasaXPS Version 2.3.16 RP 1.6. Prior to the peak fitting the background contributions were subtracted using a Shirley function.

\section{XPS Analysis}

Table S2: Summary of global atomic percentages of $\mathrm{Ti}_{3} \mathrm{C}_{2} \mathrm{~T}_{x}$ etched by $\mathrm{NH}_{4} \mathrm{HF}_{2}$ after sputtering.

\begin{tabular}{ccccccc}
\hline & Ti at $\%$ & $\mathrm{C}$ at. $\%$ & $\mathrm{~F}$ at. $\%$ & $\mathrm{O}$ at. \% Al at. \% & $\mathrm{N}$ at. $\%$ & \\
\hline $\mathrm{Ti}_{3} \mathrm{C}_{2} \mathrm{~T}_{x}$ etched by $\mathrm{NH}_{4} \mathrm{HF}_{2}$ & $37.8 \pm 0.2$ & $24.3 \pm 0.3$ & $10.4 \pm 0.2$ & $23.8 \pm 0.2$ & $2.1 \pm 0.2$ & $1.6 \pm 0.1$ \\
\hline
\end{tabular}

Table $\mathrm{S} 2$ shows the elemental analysis of a cold pressed $\mathrm{Ti}_{3} \mathrm{C}_{2} \mathrm{~T}_{x}$ etched by $\mathrm{NH}_{4} \mathrm{HF}_{2}$ after sputtering. The sample is mainly composed of $\mathrm{Ti}, \mathrm{C}, \mathrm{O}$ and $\mathrm{F}$, with a very small amount of $\mathrm{N}\left(<2\right.$ at \%.), and $\mathrm{Al}$ of about 2 at. $\%$ indicating that a fully conversion of $\mathrm{Ti}_{3} \mathrm{AlC}_{2}$ to $\mathrm{Ti}_{3} \mathrm{C}_{2} \mathrm{~T}_{x}$ was successful upon etching by $\mathrm{NH}_{4} \mathrm{HF}_{2}$. Comparing the composition with that 
of a single, double and multiple sheets of MXene reveal that the XPS is measured on bulk MXene.

Fig. S3 plots the spectra for the various elements in $\mathrm{Ti}_{3} \mathrm{C}_{2} \mathrm{~T}_{x}$, together with their peakfits. The results are summarized in Table S2.
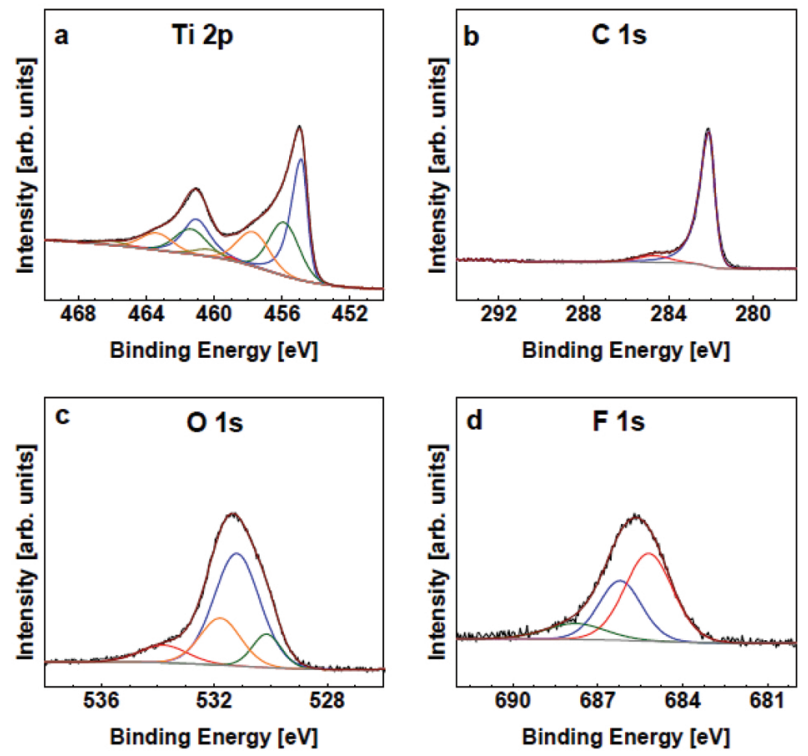

Figure S3. Component peak-fitting of XPS spectra for elements in $\mathrm{Ti}_{3} \mathrm{C}_{2} \mathrm{~T}_{x}$ etched with $\mathrm{NH}_{4} \mathrm{HF}_{2}$. Panel (a)-(d) shows spectra after $\mathrm{Ar}^{+}$sputtering, respectively.

\section{Ti $2 p$ region}

The Ti $2 p$ region, shown in Fig. S3a, was fit by the components listed in column 5 in Table S3. The majority of the species are $\mathrm{Ti}$ atoms ( $\mathrm{Ti}, \mathrm{Ti} 2+, \mathrm{Ti} 3+)$, which belong to $\mathrm{Ti}_{3} \mathrm{C}_{2}-\mathrm{O} /-$ $\mathrm{OH}_{x}$ or $\mathrm{OH}-\mathrm{H}_{2} \mathrm{O}$ and $\mathrm{Ti}_{3} \mathrm{C}_{2} \mathrm{Fx}$. These comprise $96 \%$ of the Ti $2 \mathrm{p}$ region photoemission. The other $4 \%$ is for $\mathrm{TiO}_{2}$. The Ti peak is at a binding energy of $454.9 \mathrm{eV}$, which is at a higher-binding energy compared to that of $\mathrm{Ti}_{3} \mathrm{AlC}_{2}(454.6 \mathrm{eV})$, and it is very close to the binding energy of $\mathrm{Ti}_{3} \mathrm{C}_{2} \mathrm{~T}_{x}$ thin film etched by $\mathrm{NH}_{4} \mathrm{HF}_{2} \cdot{ }^{1,2}$ This shift is due to the removal of the $\mathrm{Al}$ and the introduction of surface terminations.

The species $\mathrm{Ti}(+2) 3 \mathrm{C} 2-\mathrm{O} /-\mathrm{OH}_{x}$ or $\mathrm{OH}-\mathrm{H}_{2} \mathrm{O}$, and $\mathrm{Ti}(+3) 3 \mathrm{C} 2-\mathrm{O} /-\mathrm{OH}_{x}$ or $\mathrm{OH}-\mathrm{H}_{2} \mathrm{O}$ correspond to atoms in the two oxidation states of Ti $2+$ and $3+$, respectfully, and are similar 
to those found in $\mathrm{TiC} .{ }^{3}$

Table S3: XPS peak fitting results for $\mathrm{Ti}_{3} \mathrm{C}_{2} \mathrm{~T}_{x}$ etched by $\mathrm{NH}_{4} \mathrm{HF}_{2}$ after sputtering.

\begin{tabular}{|c|c|c|c|c|c|}
\hline Region & $\mathrm{BE}[\mathrm{eV}]^{a}$ & $\mathrm{FWHM}[\mathrm{eV}]^{a}$ & Fraction & Assigned to & Reference \\
\hline \multirow{5}{*}{ Ti 2p3/2(2p1/2) } & $454.9(461.1)$ & $0.9(1.8)$ & 0.44 & $\mathrm{C}-\mathrm{Ti}-\mathrm{O}_{x} /-(\mathrm{OH})_{x}$ or $-\mathrm{OH}_{x}-\mathrm{H}_{2} \mathrm{O}_{a d s}$ & 1 \\
\hline & $455.9(461.4)$ & $2.1(2.2)$ & 0.29 & $\mathrm{C}-\mathrm{Ti}(+2)-\mathrm{O}_{x} /-(\mathrm{OH})_{x}$ or $-\mathrm{OH}_{x}-\mathrm{H}_{2} \mathrm{O}_{a d s}$ & 1 \\
\hline & $457.6(463.3)$ & $2.2(2.2)$ & 0.21 & $\mathrm{C}-\mathrm{Ti}(+3)-\mathrm{O}_{x} /-(\mathrm{OH})_{x}$ or $-\mathrm{OH}_{x}-\mathrm{H}_{2} \mathrm{O}_{a d s}$ & 1 \\
\hline & $459.0(464.7)$ & $1.0(1.2)$ & 0.03 & $\mathrm{TiO}_{2}$ & $1,4,5$ \\
\hline & $460.3(466.0)$ & $1.8(1.6)$ & 0.02 & $\mathrm{C}-\mathrm{Ti}-\mathrm{F}_{x}$ & 1,6 \\
\hline \multirow{2}{*}{ C $1 \mathrm{~s}$} & 282.1 & 0.6 & 0.92 & $\mathrm{C}-\mathrm{Ti}-\mathrm{T}_{x}$ & $1-3$ \\
\hline & 284.7 & 1.8 & 0.08 & $\mathrm{C}-\mathrm{C}$ & 7 \\
\hline \multirow{4}{*}{$\mathrm{O}$ 1s } & 530.1 & 1.2 & 0.11 & $\mathrm{TiO}_{2}$ & 5,8 \\
\hline & 531.2 & 1.9 & 0.57 & $\mathrm{C}-\mathrm{Ti}-\mathrm{O}_{x}$ & 1,8 \\
\hline & 531.8 & 1.7 & 0.22 & $\mathrm{C}-\mathrm{Ti}-(\mathrm{OH})_{x}$ & 1,8 \\
\hline & 533.8 & 2.0 & 0.10 & $\mathrm{C}-\mathrm{Ti}-(\mathrm{OH})_{x}-\mathrm{H}_{2} \mathrm{O}_{a d s}$ & 1,8 \\
\hline \multirow{3}{*}{ F $1 \mathrm{~s}$} & 685.2 & 2.0 & 0.55 & C-Ti-Fx & 1,6 \\
\hline & 686.2 & 1.8 & 0.33 & $\mathrm{AlF}_{x}$ & 9 \\
\hline & 687.8 & 2.5 & 0.12 & $\mathrm{Al}(\mathrm{OF})_{x}$ & 9 \\
\hline
\end{tabular}

${ }^{a}$ Values in parenthesis corresponds to the $2 \mathrm{p} 1 / 2$ component.

\section{1s region}

The C 1s region shown in Fig. S3b was fit by mostly one large peak, at $282.1 \mathrm{eV}$, corresponding to $\mathrm{C}-\mathrm{Ti}-\mathrm{T}_{x}$ and small fractions for graphitic $\mathrm{C}-\mathrm{C}$ (column 5 in Table S3). The binding energy of C-Ti- $\mathrm{T}_{x}$ is slightly higher than that of $\mathrm{C}$ in $\mathrm{Ti}_{3} \mathrm{AlC}_{2}(281.5-281.8 \mathrm{eV})^{3}$ which can be attributed to any defects introduced in the Ti-C lattice due to the etching procedure. The graphitic carbon $(\mathrm{C}-\mathrm{C})$ is expected as a possible decomposition product of the etching reaction. $^{10}$

\section{O 1s region}

The $\mathrm{O}$ 1s region (Fig. S3c) was fit by components corresponding to C-Ti-O ${ }_{x}, \mathrm{C}-\mathrm{Ti}-(\mathrm{OH})_{x}$, and $\mathrm{H}_{2} \mathrm{O}_{a d s}$, which are the majority fraction of that region. Additionally a small fraction of $\mathrm{TiO}_{2}$ is present (column 5 in Table S3). The peak C-Ti-O ${ }_{x}$ at a binding energy of $531.2 \mathrm{eV}$, which is close to that of an $\mathrm{O}$ atom near to a vacant site in $\mathrm{TiO}_{2}$, i.e. defective $\mathrm{TiO}_{2}(531.5$ $\mathrm{eV}){ }^{8}$ The peak for $\mathrm{C}-\mathrm{Ti}-(\mathrm{OH})_{x}$ is located at a binding energy of $531.8 \mathrm{eV}$, which is quite close to that of $\mathrm{OH}$ groups at bridging sites on $\mathrm{TiO}_{2}$ and it is at the same binding energy of C-Ti- $(\mathrm{OH})_{x}$ for $\mathrm{Ti}_{3} \mathrm{C}_{2} \mathrm{~T}_{x}$ thin film etched by $\mathrm{NH}_{4} \mathrm{HF}_{2} \cdot{ }^{1,8}$ 
The $\mathrm{H}_{2} \mathrm{O}_{\text {ads }}$ component is presumed to arise from adsorbed water on $\mathrm{Ti}_{3} \mathrm{C}_{2} \mathrm{~T}_{x}$, likely from exposure to water during etching or washing to remove the etchant and reaction products. The binding energy of its peak $(533.8 \mathrm{eV})$ is close to that of water adsorbed on titania ( 533.5 eV). ${ }^{8}$ This species has been observed for $\mathrm{Ti}_{3} \mathrm{C}_{2} \mathrm{~T}_{x}$ thin film etched by $\mathrm{NH}_{4} \mathrm{HF}_{2}$ as well as other MXenes such as $\mathrm{Nb}_{2} \mathrm{CT}_{x}$ and $\mathrm{V}_{2} \mathrm{CT}_{x} \cdot 1,11$

\section{F 1s region}

The F 1s region (Fig. S3d) was fit by a component for a major species corresponding to $\mathrm{C}-\mathrm{Ti}_{x}$ (at a binding energy of $685.2 \mathrm{eV}$ ), viz. Ti-atoms are directly bonded to F-atoms. This binding energy is $0.4 \mathrm{eV}$ higher than that of $\mathrm{TiF}_{4},{ }^{6}$ a similar compound that should have a value close to that of the $\mathrm{Ti}-\mathrm{F}$ bond in $\mathrm{Ti}_{3} \mathrm{C}_{2} \mathrm{~F}_{x}$. Several minor species corresponding to $\mathrm{TiO}_{2}-\mathrm{F}, \mathrm{AlF}_{x}$, and $\mathrm{Al}(\mathrm{OF})_{x}$ were also fit in the $\mathrm{F}$ 1s region. The $\mathrm{AlF}_{x}$ and $\mathrm{Al}(\mathrm{OF})_{x}$ species are present as byproducts of the synthesis procedure.

Combining the elemental analysis shown in Table S2 and the fractions of various MXene components obtained from the high resolution XPS spectra of Ti 2p, C 1s, O 1s and F 1s, the general formula of $\mathrm{Ti}_{3} \mathrm{C}_{2} \mathrm{~T}_{x}$ is obtained to be $\mathrm{Ti}_{3} \mathrm{C}_{1.7} \mathrm{O}_{1.1}(\mathrm{OH})_{0.4} \mathrm{~F}_{0.4}$.

\section{The presence of $\mathrm{N}$ and $\mathrm{F}$}

The spectra from the single, double and multiple sheets show a small amount of $\mathrm{N}$ which is constant over the various sheets (see Fig. S4). N may originate from the etching process as intercalated species, which has not dissociated, or from the parent MAX phase. However, N incorporation into carbide MAX phases has not been reported.

In this study $\mathrm{F}$ is not visible on the single sheet, but a small amount is found in the double and the multiple sheets (see Fig. S4). Similar to O, F is found on surfaces of MXene ${ }^{1}$ and the present lack of $\mathrm{F}$ on the single sheet indicate that $\mathrm{F}$ may have dissociated from the surfaces after the etching process as a consequence of its volatile nature, while the remaining 
$\mathrm{F}$ is trapped between the MXene sheets.

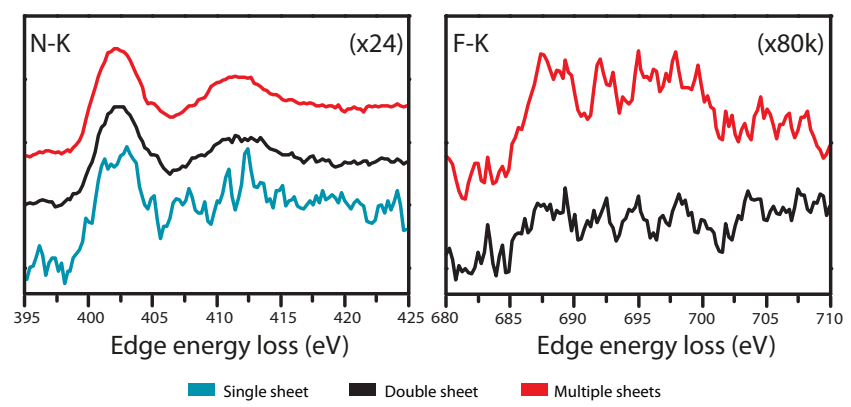

Figure S4. EELS spectra of N and F. (a) N for single, double and multiple sheets, and (b) $\mathrm{F}$ for double and multiple sheets.

\section{References}

(1) Halim, J.; Lukatskaya, M. R.; Cook, K. M.; Lu, J.; Smith, C. R.; Näslund, L.; May, S. J.; Hultman, L.; Gogotsi, Y.; Eklund, P.; Barsoum, M. W. Chem. Mater. 2014, 26, 23742381.

(2) Myhra, S.; Crossley, J. A. A.; Barsoum, M. W. Journal of Physics and Chemistry of Solids 2001, 62, 811-817.

(3) Schier, V.; Michel, H. J.; Halbritter, J. Fresenius' journal of analytical chemistry 1993, 346, 227-232, J2: Fresenius J Anal Chem.

(4) Santerre, F.; Khakani, M. A. E.; Chaker, M.; Dodelet, J. P. Applied Surface Science 1999, $148,24-33$.

(5) Diebold, U.; Madey, T. E. Surface Science Spectra 1996, 4, 227-231.

(6) Sultana, T.; Georgiev, G. L.; Auner, G.; Newaz, G.; Herfurth, H. J.; Patwa, R. Applied Surface Science 2008, 255, 2569-2573.

(7) Jayaweera, P. M.; Quah, E. L.; Idriss, H. The Journal of Physical Chemistry C 2007, 111, 1764-1769. 
(8) Yamamoto, S.; Bluhm, H.; Andersson, K.; Ketteler, G.; Ogasawara, H.; M Salmeron and, A. J. Phys.: Condens. Matter 2008, 20, 184025.

(9) Ernst, K. H.; Grman, D.; Hauert, R.; Holländer, E. Surface and Interface Analysis 1994, 21, 691-696.

(10) Lukatskaya, M. R.; Halim, J.; Dyatkin, B.; Naguib, M.; Buranova, Y. S.; Barsoum, M. W.; Gogotsi, Y. Angewandte Chemie International Edition 2014, 53, 48774880.

(11) Naguib, M.; Halim, J.; Lu, J.; Cook, K. M.; Hultman, L.; Gogotsi, Y.; Barsoum, M. W. J. Am. Chem. Soc. 2013, 135, 15966-15969. 